\title{
A Review on Active Packaging: An Innovation in Food Packaging
}

\begin{abstract}
Innovative packaging such as active packaging is the result of consumers demand for packaging that is more advanced and creative than what is currently offered. Active packaging aiming at extending shelf life or improving safety while maintaining quality is progressing towards the incorporation of natural active agents into more sustainable packaging materials. Depending on the requirements of packed food, the application of appropriate active packaging systems can significantly reduce food quality deterioration. Different active packaging systems are Oxygen scavengers, Carbon dioxide emitters and scavenger, Ethylene scavengers, Ethanol emitters, Moisture absorbers, Antimicrobial agents, Flavour/odour absorbers, Temperature-controlled packaging.
\end{abstract}

K. A. Mane

Keywords-Active packaging, Oxygen scavengers, Carbon dioxide emitters and scavenger, Ethylene scavengers, Ethanol emitters, Moisture absorbers, Antimicrobial agents, Flavour/odour absorbers, Temperature-controlled packaging.

\section{INTRODUCTION}

Food packaging exists to make our lives easier. We need packaging to contain food protect food from the outside environment, for convenience and to communicate information to consumers about the food inside the package. Although traditional packaging covers the basic needs of food containment, advances in food packaging are both anticipated and expected. The main purpose of food packaging is to protect the food from microbial and chemical contamination, oxygen, water vapour and light. The type of packaging used therefore has an important role in determining the shelf life of a food. Active packaging does more than simply provide a barrier to outside influences. It can control, and even react to, events taking place inside the package (Kale et al., 2003).

Society is becoming increasingly complex and innovative packaging such as active packaging is the result of consumers demand for packaging that is more advanced and creative than what is currently offered. New concepts of active and intelligent packaging are due to play an increasingly important role by offering numerous and innovative solutions for extending the shelf-life or maintain, improve or monitor food quality and safety (Gontard, 2006). Active packaging systems are developed with the goal of extending shelf life for foods and increasing the period of time that the food is high quality. Active packaging technologies include some physical, chemical, or biological action which changes interactions between a package, product, and/or headspace of the package in order to get a desired outcome (Yam et al., 2005). Depending on the requirements of packed food, the application of appropriate active packaging systems can significantly reduce food quality deterioration. Food conditions that may play an important role in the shelf life of packed food include physiological processes (e.g. respiration of fresh fruits and vegetables), chemical reactions (e.g. lipid oxidation), physical processes (e.g. dehydration) and microbiological aspects (e.g. spoilage by microorganisms).

\section{What is Active Packaging?}

Active packaging refers to the incorporation of certain material into packaging for maintaining and extending product shelf life. Packaging may be termed active when it performs some desired role in food preservation other than providing an inert barrier to external conditions (Roony, 1995; Hotchkiss, 1994).

\section{Active Packaging vs. Intelligent Packaging}

Active packaging is not synonymous with intelligent or smart packaging which refers to the packaging which is capable of sensing and providing information about the function and properties of packaged food. Intelligent packaging devices include time and temperature indicators, gas sensing dyes, microbial growth indicators, physical shock indicators etc (Summers, 1992; Day, 2001).

\section{Active Packaging Systems}

Active packaging is sensing followed by the manipulation of the environment in the package to better retain food content microbiological or bio chimerical quality. Different active packaging systems are listed below.
$\square$ Oxygen scavengers
$\square$ Carbon dioxide emitters and scavenger
$\square$ Ethylene scavengers
$\square$ Ethanol emitters
$\square$ Moisture absorbers 

Antimicrobial agents
$\square$ Temperature-controlled packaging

$\square$ Flavour/odour absorbers

Table.1: Selected examples of active packaging systems (Day, 2003)

\begin{tabular}{|c|c|c|}
\hline Active packaging system & Mechanisms & Food applications \\
\hline Oxygen scavengers & $\begin{array}{l}\text { 1. Iron based } \\
\text { 2. metal/acid } \\
\text { 3. Metal (e.g. platinum) catalyst } \\
\text { 4. Ascorbate/metallic salts } \\
\text { 5. Enzyme based }\end{array}$ & $\begin{array}{l}\text { Bread, cakes, cooked rice, } \\
\text { biscuits, pizza, pasta, cheese, } \\
\text { cured meats and fish, coffee, } \\
\text { snack foods, dried foods and } \\
\text { beverages }\end{array}$ \\
\hline $\begin{array}{l}\text { Carbon dioxide } \\
\text { scavengers/emitters }\end{array}$ & $\begin{array}{l}\text { 1. Iron oxide/calcium hydroxide } \\
\text { 2. Ferrous carbonate/metal halide } \\
\text { 3. Calcium oxide/activated charcoal } \\
\text { 4. Ascorbate/sodium bicarbonate }\end{array}$ & $\begin{array}{l}\text { Coffee, fresh meats and fish, } \\
\text { nuts and other snack food } \\
\text { products and sponge cakes }\end{array}$ \\
\hline Ethylene scavengers & $\begin{array}{l}\text { 1. Potassium permanganate } \\
\text { 2. Activated carbon } \\
\text { 3. Activated clays/zeolites }\end{array}$ & $\begin{array}{l}\text { Fruit, vegetables and other } \\
\text { horticultural products }\end{array}$ \\
\hline Ethanol emitters & $\begin{array}{l}\text { 1. Alcohol spray } \\
\text { 2. Encapsulated ethanol }\end{array}$ & $\begin{array}{l}\text { Pizza crusts, cakes, bread, } \\
\text { biscuits, fish and bakery } \\
\text { products }\end{array}$ \\
\hline Moisture absorbers & $\begin{array}{l}\text { 1. PVA blanket } \\
\text { 2. Activated clays and minerals } \\
\text { 3. Silica gel }\end{array}$ & $\begin{array}{l}\text { Fish, meats, poultry, snack } \\
\text { foods, cereals, dried foods, } \\
\text { sandwiches, fruit and } \\
\text { vegetables }\end{array}$ \\
\hline Antimicrobial agents & $\begin{array}{l}\text { 1. organic acids } \\
\text { 2. silver zeolite } \\
\text { 3. spice and herb extracts } \\
\text { 4. BHA/BHT antioxidants } \\
\text { 5. vitamin E antioxidant } \\
\text { 6. volatile chlorine dioxide/ } \\
\text { sulphur dioxide }\end{array}$ & $\begin{array}{l}\text { Cereals, meats, fish, bread, } \\
\text { cheese, snack foods, fruit and } \\
\text { vegetables }\end{array}$ \\
\hline Flavour/odour adsorbers & $\begin{array}{l}\text { 1. cellulose triacetate } \\
\text { 2. acetylated paper } \\
\text { 3. citric acid } \\
\text { 4. ferrous salt/ascorbate } \\
\text { 5. activated carbon/clays/zeolites }\end{array}$ & $\begin{array}{l}\text { Fruit juices, fried snack } \\
\text { foods, fish, cereals, poultry, } \\
\text { dairy products and fruit }\end{array}$ \\
\hline $\begin{array}{l}\text { Temperature control } \\
\text { Packaging }\end{array}$ & $\begin{array}{l}\text { 1. non-woven plastics } \\
\text { 2. double walled containers } \\
\text { 3. hydro fluorocarbon gas } \\
\text { 4. Lime/water } \\
\text { 5. ammonium nitrate/water }\end{array}$ & $\begin{array}{l}\text { Ready meals, meats, fish, } \\
\text { poultry and beverages }\end{array}$ \\
\hline
\end{tabular}

\section{Oxygen scavengers}

The presence of $\mathrm{O}_{2}$ in a packed food is often a key factor that limits the shelf life of a product. Oxidation can cause changes in flavor, color, and odor, as well as destroy nutrients and facilitate the growth of aerobic bacteria, molds, and insects. Therefore, the removal of $\mathrm{O}_{2}$ from the package headspace and from the solution in liquid foods and beverages has long been a target of the food-packaging scientists. The deterioration in quality of $\mathrm{O}_{2}$ sensitive products can be minimized by recourse to $\mathrm{O}_{2}$ scavengers that remove the residual $\mathrm{O}_{2}$ after packing. The term oxygen scavenger has been applied to materials incorporated into package structures that chemically combine with, and thus effectively remove, oxygen from the inner package 
environment. In turn, scavengers may remove oxygen from the food product itself through diffusion resulting from differential partial pressure actions. One implication that might be derived from this list of definitions is that scavengers are fast-acting, high-capacity oxygen interceptors, capable of eliminating relatively large volumes of oxygen and continuing their action indefinitely as long as the scavenger is present. Existing $\mathrm{O}_{2}$ scavenging technologies are based on oxidation of one or more of the following substances: iron powder, ascorbic acid, photosensitive dyes, enzymes (such as glucose oxidase and ethanol oxidase), unsaturated fatty acids (such as oleic, linoleic and linolenic acids), rice extract, or immobilized yeast on a solid substrate (Floros et al.1997).

Applications of oxygen scavengers could be in packaged pasta, milk powder, biscuits, etc. These scavengers are usually in the form of sachets. They scavenge or capture residual oxygen from inside the packaging (from the environment surrounding the foodstuff or from the foodstuff itself) to reduce exposure to oxygen. Exposure to oxygen may result in microbiological growth on the food, chemical changes to the food, etc. An oxygen scavenger is meant to reduce these effects thereby prolonging the shelf-life of the foodstuffs (Anon, 2009).

\section{Carbon dioxide emitters and scavenger}

Carbon Dioxide is known to suppress microbial activity. Relatively high $\mathrm{CO}_{2}$ levels (60 to 80\%) inhibit microbial growth on surfaces and in turn, prolong shelf life. Therefore, a complementary approach to $\mathrm{O}_{2}$ scavenging is the impregnation of a packaging structure with a $\mathrm{CO}_{2}$ generating system or the addition of the latter in the form of a sachet. Since the permeability of $\mathrm{CO}_{2}$ is 3 to 5 times higher than that of $\mathrm{O}_{2}$ in most plastic films, it must be continuously produced to maintain the desired concentration within the package. $\mathrm{A} \mathrm{CO}_{2}$ generator is only useful in certain applications such as fresh meat, poultry, fish and cheese packaging. In food products for which the volume of the package and its appearance are critical, an $\mathrm{O}_{2}$ scavenger and $\mathrm{CO}_{2}$ generator could be used together (Smith et al., 1995) in order to prevent package collapse as a result of $\mathrm{O}_{2}$ absorption.

Although carbon dioxide often exerts a microbiological inhibitory effect in modified atmosphere packaging, excess carbon dioxide may at times adversely affect the product or counter the inhibitory effect. Therefore, some foodpreservation packaging systems are engineered to remove carbon dioxide (Brody et al., 2001).

\section{Ethylene scavengers}

The control of ethylene in stored conditions plays a key role in prolonging the postharvest life of many types of fresh produce (Terry et. al. 2007). Most fruits and vegetables release ethylene after they are harvested. Ethylene is a phytohormone that initiates and accelerates ripening, produces softening and degradation of chlorophylls, and inevitably leads to deterioration of fresh or minimally processed fruits and vegetables. Ethylene scavengers are useful for preserving ethylene-sensitive fruits and vegetables such as apples, bananas, mangos, tomatoes, onions, carrots (Prasad and Kochhar, 2014).

Ethylene is a plant growth regulator which accelerates the respiration rate and subsequent senescence of horticultural products such as fruit, vegetable and flowers. Many of the effects of ethylene are necessary, e.g. induction of flowering in pineapples, colour development in citrus fruits, bananas and tomatoes, stimulation of root production in baby carrots and development of bitter flavour in bulk delivered cucumbers, but in most horticultural situations it is desirable to remove ethylene or to suppress its negative effects. Consequently, much research has been undertaken to incorporate ethylene scavengers into fresh produce packaging and storage areas. Some of this effort has met with commercial success, but much of it has not (Abeles et al., 1992).

One of the main mechanisms of action of ethylene scavengers is based on the use of potassium permanganate, which oxidizes ethylene to carbon dioxide and water. The typical permanganate content is between $4 \%$ and $6 \%$ (Abe and Watada, 1991). Potassium permanganate oxidizes ethylene and changes color from purple to brown, and thus, a color change indicates its residual ethylene absorbing capacity, but because of its toxicity potassium permanganate cannot be used in direct contact with food. Other systems are based on the ability of certain materials to absorb ethylene, alone or with any oxidizing agent. For example, palladium has been shown to have a higher ethylene adsorption capacity than permanganate-based scavengers in situations of high relative humidity (Smith et al. 2009).

LDPE and HDPE polyethylene films as packaging material are able to absorb ethylene; ethanol, ethyl acetate, ammonia, and hydrogen sulfide are used in food industry. These films keep food fresh for longer and eliminate odors (Prasad and Kochhar, 2014).

\section{Ethanol emitters}

Ethanol is used routinely in medical and pharmaceutical packaging applications, indicating its potential as a vapor phase inhibitor (Smith et al.,1987). It prevents microbial 
spoilage of intermediate moisture foods, cheeses, and bakery products. It also reduces the rate of staling and oxidative changes (Seiler, 1989). Ethanol has been shown to extend the shelf life of bread, cake and pizza when sprayed onto product surfaces prior to packaging. Sachets containing encapsulated ethanol release its vapor into the packaging headspace thus maintaining the preservative effect (Labuza and Breene, 1989).

An ethanol-generating technology was originally developed in Japan whereby food grade ethanol is encapsulated in a fine inert powder inside a sachet. The rate of ethanol vapor release can be tailored by controlling the permeability of the sachet (Smith et al., 1995).

\section{Moisture absorbers}

Excess moisture is a major cause of food spoilage. Soaking up moisture by using various absorbers or desiccants is very effective in maintaining food quality and extending shelf life by inhibiting microbial growth and moisture related degradation of texture and flavor. For packaged dried food applications, desiccants such as silica gel, calcium oxide and activated clays and minerals are typically contained within tear-resistant permeable plastic sachets. For dualaction purposes, these sachets may also contain activated carbon for odour adsorption or iron powder for oxygen scavenging (Rooney, 1995).

Desiccants protect sensitive products against water and humidity. Offered in clay, molecular sieve, and silica gel forms, they absorb moisture that enters or remains in a package. Probably the best known internal package moisture absorbers are conventional silica gels, which can absorb up to $35 \%$ of their own weight in water. Silica gels are useful to maintain dry conditions within packages of dry foods, down to below 0.2 water activity. Molecular sieves such as zeolites can absorb up to $24 \%$ of their weight in water, i.e., they have a high affinity for moisture. When dry, they can also pick up odors. When wet, they tend to surrender these odors. Cellulose fiber pads are often used to remove water, as, for example, soaker pads in the bottom of meat, poultry, and fresh produce trays. They can also surrender water when they are saturated. As such, cellulose fiber pads can be employed to add water to the internal package environment (Brody et al., 2001).

\section{Flavour/odour absorbers}

The removal of odors from the interior of food packages may be both beneficial and detrimental. In the latter case, aroma capture may remove desirable components of the contained food, as when some interior polyolefin package components "scalp" aromatic notes from contained product contents such as orange juice. One function of the package, therefore, is to block the bloss of desirable odor from the product. This is also often the primary objective of barrier packaging. In some instances, the aroma-removal properties are unintentionally incorporated into active packaging technologies, a topic discussed below. The issue of the benefits of odor/aroma removal is, however, significant in the realm of active packaging. Many foods such as fresh poultry and cereal products develop what are referred to as confinement odors. Very slight and generally insignificant but nevertheless detectable deterioration odors, such as sulfurous compounds from protein/amino acid breakdown or aldehyde/ketone compounds from lipid oxidation or anaerobic glycolysis, may form during product distribution. These odors are trapped within gas-barrier packaging so that, when the package is opened, they are released to be detected by consumers. These relatively harmless odors, which generally do not signal any significant spoilage, may be cause for rejection even though they dissipate into the surrounding air within seconds. One reason for odor removal from the interior of packages would be to obviate the potentially adverse effects of these "confinement odors." A second reason for incorporating odor removers into packages is to obviate the effects of odors developed in the package materials themselves. During plastic processing, i.e., extrusion, molding, film and sheet blowing, or casting, some polyolefin components may tend to break down or oxidize into short chain and often odorous hydrocarbon compounds. Antioxidants are often included in the polyolefin-processing additive package to try to minimize the undesirable odor effects (Brody et al., 2001).

\section{Antimicrobial Agents}

Antimicrobial food packaging materials have to extend the lag phase and reduce the growth rate of microorganisms in order to extend shelf life and to maintain product quality and safety (Han, 2000). Alternatives to direct additives for minimizing the microbial load are canning, aseptic processing and MAP. However, canned foods cannot be marketed as "fresh". Aseptic processing may be expensive and hydrogen peroxide, which is restricted in level by regulatory agencies, is often used as a sterilizing agent. In certain cases, MAP can promote the growth of pathogenic anaerobes and the germination of spores, or prevent the growth of spoilage organisms which indicate the presence of pathogens (Farber, 1991). If packaging materials have self-sterilizing abilities due to their own AM effectiveness, the need for chemical sterilization of the packages may be obviated and the aseptic packaging process simplified (Hotchkiss, 1997). 
Food packages can be made AM active by incorporation and immobilization of AM agents or by surface modification and surface coating. Present plans envisage the possible use of naturally derived AM agents in packaging systems for a variety of processed meats, cheeses, and other foods, especially those with relatively smooth product surfaces that come in contact with the inner surface of the package. This solution is becoming increasingly important, as it represents a perceived lower risk to the consumer (Nicholson, 1998).

Antimicrobial films can be classified in 2 types: (1) those that contain an AM agent that migrates to the surface of the food, and (2) those that are effective against surface growth of microorganisms without migration (Suppakul et al., 2003).

\section{Temperature-controlled packaging}

Temperature control active packaging includes the use of innovative insulating materials, self-heating and selfcooling cans. For example, to guard against undue temperature abuse during storage and distribution of chilled foods, special insulating materials have been developed. One such material is Thinsulate, which is a special nonwoven plastic with many air pore spaces. Another approach for maintaining chilled temperatures is to increase the thermal mass of the food package so that it is capable of withstanding temperature rises. Self-heating cans and containers have been commercially available for decades and are particularly popular in Japan. Self-heating aluminium and steel cans and containers for sake, coffee, tea and ready meals are heated by an exothermic reaction which occurs when lime and water positioned in the base are mixed (Day, 2003).

\section{Food safety, consumer acceptability and regulatory issues}

At least four types of food safety and regulatory issues related to active packaging of foods need to be addressed. First, any need for food contact approval must be established before any form of active packaging is used. Second, it is important to consider environmental regulations covering active-packaging materials. Third, there may be a need for labeling in cases where active packaging may give rise to consumer confusion. Fourth, it is pertinent to consider the effects of active packaging on the microbial ecology and safety of foods (Rooney, 1995).

Food contact approval will often be required because active packaging may affect foods in two ways. Active packaging substances may migrate into the food or may be removed from it. Migrants may be intended or unintended. Intended migrants include antioxidants, ethanol and antimicrobial preservatives which would require regulatory approval in terms of their identity, concentration and possible toxicology effects. Unintended migrants include various metal compounds which achieve their active purpose inside packaging materials but do not need to, or should not, enter foods. Food additive regulations require identification and quantification of any such unintended migration (Day, 2003).

Environmental regulations covering reuse, recycling, and identification to assist in recycling or the recovery of energy from active packaging materials need to be addressed on a case-by-case basis (Coles et al. 2003).

Food labeling is currently required to reduce the risk of consumers ingesting the contents of oxygen scavenger sachets or other in-pack active-packaging devices. Some active packages may look different from their passive counterparts. Therefore it may be advisable to use appropriate labeling to explain this difference to the consumer even in the absence of regulations. Finally, it is very important for food manufacturers using certain type of active packaging to consider the effects this will have on the microbial ecology and safety of foods. For example, removing all the oxygen from within the packs of high aw chilled perishable food products may stimulate the growth of anaerobic pathogenic bacteria such as Clostridium botulinum (Betts, 1996).

\section{CONCLUSIONS}

Active packaging technologies offer new opportunities for the food industry, in the preservation of foods. It is an emerging and exciting area of food technology that can confer many preservation benefits on a wide range of food products. Active packaging is a technology developing a new trust because of recent advances in packaging, material science and new consumer demands. The objectives of this technology are to maintain sensory quality and extend the shelf life of foods whilst at the same time maintaining nutritional quality and ensuring microbial safety. Active packaging systems can be successfully used to increase the shelf life of processed foods and are categorized into adsorbing and releasing systems (for example, oxygen scavengers, ethylene scavengers, moisture absorbers, flavor and odor absorbers or releasers, antimicrobials etc.). However, the development and implementation of this type of packaging will depend on the acceptance and costeffectiveness for industry and consumers. 


\section{REFERENCES}

[1] Abe, K. and Watada, A. Ethylene absorbent to maintain quality of lightly processed fruits and vegetables. J. Food Sci. 1991, 56, 1589-1592

[2] Abeles, F.B., Morgan, P.W. and Saltveit, M.E. (1992) Ethylene in Plant Biology, Academic Press Ltd, London, UK.

[3] Anon, 2009 .EU Guidance to the Commission Regulation (EC) No 450/2009 of 29 May 2009 on active and intelligent materials and articles intended to come into contact with food. (http://ec.europa.eu/)

[4] Betts, G.D. (1996) Code of Practice for the Manufacture of Vacuum and Modified Atmosphere Packaged Chilled Foods with Particular Regards to the Risks of Botulism. Guideline No. 11, Campden \& Chorleywood Food Research Association, Chipping Campden, Glos., UK.

[5] Brody A.R., E.R. Strupinsky, L.R. Kline (2001) Active Packaging for Food Applications, CRC Press

[6] Coles R., McDowell D., Food (2003) .J .Kirwan M packaging TechnologyBlackwell Publishing, CRC Press, Oxford pp. 298-299

[7] Day B.P.F., 2001. Active packaging - a fresh approach. J. Brand Technol. 1(1),

[8] Day B. P. F. (2003), Active packaging. Food Packaging Technology. Blackwell Publishing pp 282300

[9] Farber JM. 1991. Microbiological aspects of modified atmosphere packaging: A review. J Food Prot 54(1):58-70

[10]Floros J.D., L.L. Dock, J.H. Han. 1997. Active packaging technologies and applications. Food Cosmet Drug Package 20(1):10-7.

[11] Gontard N., 2006, Tailor made food packaging concept. In: IUFoST, 13th World Congress of Food Science and Technology, Food is Life, 17e21 September 2006, Nantes, France

[12] Han J. H. 2000. Antimicrobial food packaging. Food Technology 54(3):56-65.

[13] Hotchkiss JH. 1997. Food-packaging interactions influencing quality and safety. Food Add Contamin 14(6-7):601-7. Huang LJ, Huang

[14] Kale V., Jani K., Rangaprasad R. and Vasudeo Y. (2003) Evaluation of performance of additives used in LDDPE films for active packaging applications. Addcon $9^{\text {th }}$ International Plastic Additives and Modifiers Conference.

[15]Labuza TP, Breene WM. 1989. Applications of active packaging for improvement of shelf-life and nutritional quality of fresh and extended shelf-life foods. J Food Proc Preserv 13(1):1-69.

[16] Nicholson MD. 1998. The role of natural antimicrobials in food packaging biopreservation. J Plastic Film Sheeting 14(3):234-41.

[17] Prasad P. and Kochhar A. Active Packaging in Food Industry: A Review IOSR Journal of Environmental Science, Toxicology and Food Technology (IOSRJESTFT) Volume 8, Issue 5 Ver. III (May. 2014), PP 01-07(http://www.iosrjournals.org)

[18] Rooney ML. 1995. Active packaging in polymer films. In: Rooney ML, editor. Active food packaging. Glasgow: Blackie Academic and Professional. p 74110.

[19] Seiler DAL. 1989. Modified atmosphere packaging of bakery products. In: Brody AL, editor. Controlled/ modified atmosphere/vacuum packaging of foods. Trumbull, Conn.: Food and Nutrition Press, Inc. p 119-34.

[20] Smith J. P, Ooraikul B, Koersen WJ, van de Voort FR, Jackson ED, Lawrence RA. 1987. Shelf-life extension of a bakery product using ethanol vapor. Food Microbiol 4(4):329-37.

[21] Smith, A.J., Poulston, S., Rowsell, L., Terry, L.A. and Anderson, J.A. A New palladium-based ethylene scavenger to control ethylene-induced ripening of climacteric fruit. Platin. Met. Rev. 2009, 53, 112-122.

[22] Smith J. P, Hoshino J, Abe Y. 1995. Interactive packaging involving sachet technology. In: Rooney ML, editor. Active food packaging. Glasgow: Blackie Academic and Professional. p 143-73.

[23] Summers, L. 1992, Intelligent Packaging. 1992, Centre for Exploitation of Science and Technology, London, UK.

[24] Suppakul P., J. Miltz, K. Sonneveld and S. W. Bigger, (2003) Active Packaging Technologies with an Emphasis on Antimicrobial Packaging and its Applications Journal of Food Science: Concise Reviews and Hypotheses in Food Science Vol. 68(2) Institute of Food Technologists

[25] Terry, L.A., Ilkenhans, T., Poulston, S., Rowsell, L. and Smith, A.J. (2007) Development of new palladium-promoted ethylene scavenger. Postharvest Biol. Technol., 45, 214-220.

[26] Yam, K. L., Takhistov, P. T., and Miltz, J. 2005. Intelligent packaging: concepts and applications. Journal of Food Science. 70: R1R10 